\title{
INFLUENCES OF TORQUE AND JOINT ANGLE ON HEART RATE RESPONSES DURING ISOMETRIC EXERCISE IN YOUNG MEN
}

\author{
Quitério RJ ${ }^{1,5,6}$, Moraes FR ${ }^{1}$, Oliveira L ${ }^{2}$, Teixeira LC ${ }^{3}$, Gallo Jr L ${ }^{4}$, Catai AM ${ }^{1}$ e Silva E ${ }^{1,5}$ \\ ${ }^{1}$ Laboratório de Fisioterapia Cardiovascular, Departamento de Fisioterapia, Universidade Federal de São Carlos - \\ UFSCar, São Carlos, SP - Brasil \\ ${ }^{2}$ Departamento de Física, UFSCar \\ ${ }^{3}$ Departamento de Bioengenharia, Escola de Engenharia de São Carlos, Universidade de São Paulo - USP, São Carlos, \\ SP - Brasil \\ ${ }^{4}$ Divisão de Cardiologia, Departamento de Clínica Médica, Hospital das Clínicas, Faculdade de Medicina de Ribeirão \\ Preto, USP, Ribeirão Preto, SP - Brasil \\ ${ }^{5}$ Faculdade de Ciências da Saúde, Universidade Metodista de Piracicaba, Piracicaba, SP - Brasil \\ ${ }^{6}$ Faculdades Integradas FAFIBE, Bebedouro, SP - Brasil \\ Correspondência para: Ester Silva, UFSCar, Departamento de Fisioterapia, Núcleo de Pesquisa em Exercício Físico, Via \\ Washington Luis, Km 235, CP 676, CEP 13565-905, São Carlos, SP - Brasil, e-mail: esters@power.ufscar.br
}

Recebido: 30/01/2006 - Revisado: 25/08/2006 - Aceito: 29/03/2007

\begin{abstract}
Objective: To evaluate the influence of joint angle on heart rate (HR) responses induced by isometric exercise. Method: Ten healthy men (23.8 \pm 2.5 years old) underwent isometric maximum voluntary contraction (MVC) tests lasting 10 sec using an electronic dynamometer under the following experimental conditions: knee extension at angles of $60^{\circ}$ and $90^{\circ}$ and knee flexion at angles of $30^{\circ}$ and $90^{\circ}$ angles. Their HR was recorded at rest (65 sec), during MVC (10 sec) and during the recovery period $(120 \mathrm{sec})$. The data on mean maximum torque (MMT) and HR variation $(\Delta \mathrm{HR})$ were analyzed using the Friedman test with the Dunn post-hoc test, and their correlation was analyzed using the Spearman test $(\alpha=0.05)$. Results: 1$)$ MMT was significantly higher at $60^{\circ}$ and $90^{\circ}$ knee extension than at $30^{\circ}$ and $90^{\circ}$ knee flexion $(\mathrm{p}<0.05)$, while no significant differences were found between the two extension angles or between the two flexion angles; 2) $\Delta \mathrm{HR}$ was similar under all the experimental conditions; 3) No correlation was found between MMT and $\Delta \mathrm{HR}$. Conclusion: The data suggest that the rapid increase in HR during the 10 sec of isometric MVC does not depend on the joint angle or the morphofunctional differences between the two muscle groups studied.
\end{abstract}

Key words: heart rate; torque; isometric exercise; knee flexion and extension.

\section{RESUMO}

\section{Influência do torque e do ângulo articular nas respostas da freqüência cardíaca durante exercício isométrico em homens jovens}

Objetivo: Avaliar a influência do ângulo articular nas respostas da freqüência cardíaca (FC) induzida pelo exercício isométrico. Métodos: Dez homens saudáveis (23,8 \pm 2,5 anos) foram submetidos a testes de contração voluntária máxima (CVM) isométrica, durante 10s, em um dinamômetro eletrônico, nas seguintes condições experimentais: extensão do joelho nos ângulos de $60^{\circ}$ e $90^{\circ}$ e flexão do joelho nos ângulos de $30^{\circ}$ e $90^{\circ}$. A freqüência cardíaca foi registrada durante o repouso (65s), durante a CVM (10s) e durante o período de recuperação (120s). Os dados de torque médio máximo (TMM) e de variação da FC ( $\Delta \mathrm{FC}$ ) foram analisados usando teste de Friedman, com pós-teste de Dunn, e sua correlação foi analisada usando o teste de Spearman $(\alpha=0,05)$. Resultados: 1) TMM foi significativamente maior nos ângulos de $60^{\circ}$ e $90^{\circ}$ de extensão em relação aos ângulos de $30^{\circ}$ e $90^{\circ}$ de flexão $(\mathrm{p}<0,05)$, enquanto entre os dois ângulos de flexão e entre os dois de extensão não foram encontradas diferenças significativas; 2) $\Delta \mathrm{FC}$ foi similar em todas as condições experimentais; 3) Não foi encontrada correlação entre TMM e $\Delta \mathrm{FC}$. Conclusões: Os dados sugerem que a elevação rápida da FC, durante os 10 s de CVM isométrica, independe do ângulo articular e das diferenças morfofuncionais entre os dois grupos musculares estudados.

Palavras-chave: freqüência cardíaca; torque; exercício isométrico; flexão e extensão do joelho. 


\section{INTRODUCTION}

The autonomic efferent mechanisms responsible for the tachycardia induced by isometric exercise are well known. Both vagal withdrawal and sympathetic stimulation of the sinus node may contribute in different degrees towards exercise tachycardia, depending on the duration and intensity of the isometric effort ${ }^{1}$.

The central efferent and peripheral afferent pathways interact and mediate changes in the autonomic activity level of the heart ${ }^{1,2,3}$, thereby leading to a sudden increase in heart rate (HR) that is manifested as early as the first beat after the beginning of exercise ${ }^{4}$. In the literature, the initial rapid increase in HR that is observed within the first 10 seconds of isometric exercise has been attributed to an inhibition of vagal tonus of the heart due to central pathway irradiation ${ }^{1,4,5}$.

Maciel et al. ${ }^{1}$ examined the relative contribution of the efferent components of the autonomic nervous system towards regulating tachycardia that was induced by isometric exercise. They analyzed this under control conditions and after pharmacological blockade with atropine or propranolol, and observed that parasympathetic blockade decreased heart rate responses to isometric exercise during the first $10 \mathrm{sec}$, whereas sympathetic blockade markedly modified the HR after 10 sec of effort. These results showed that the initial phase depends on rapid withdrawal of the parasympathetic influence.

Studies on the HR response to isometric exercise involving different muscle groups (different mass and fiber types) and joint angle have shown conflicting results, with regard to heart rate responses. Fisher et al. ${ }^{6}$ showed that, for isometric exercise at maximum voluntary contraction (MVC), the joint angle influences fiber length during muscle action. According to the literature ${ }^{7,8,9}$, this change in fiber length alters the recruitment pattern and frequency of motor unit firing for producing and/or maintaining voluntary contraction. Some authors have suggested that the highest torque is reached when muscle fibers are shortest ${ }^{10,11,12}$, and that this is attributable to the interaction between physiological factors such as the length-tension relationship (sarcomere length and number of active cross-bridges) and mechanical factors such as the length of the lever arm. In contrast, other authors ${ }^{7,13,14}$ observed the highest torque during MVC when the muscle was in an elongated position. In addition, studies in the literature have demonstrated that alterations in the joint angle do not influence the torque ${ }^{15}$ or the magnitude of HR responses at the same stress level ${ }^{15,16}$.

Given these contradictions and uncertainties in previous research, the objective of the present study was to evaluate the magnitude of the heart rate (HR) responses induced by isometric exercise consisting of knee extension and flexion and the influence of joint angle on these responses.

\section{METHODS}

\section{Subjects}

Ten healthy young men aged $23.8 \pm 2.5$ years with active lifestyles (mean of $6.1 \pm 1.3$ hours of physical activity per week) and right-leg dominance were studied. They were all nonsmokers and did not use any drugs. Their anthropometric characteristics, expressed as mean and standard deviation, were: height $181.7 \pm 4.5 \mathrm{~cm}$, weight $78.51 \pm 5.3 \mathrm{~kg}$, body mass index $21.4 \pm 1.3 \mathrm{~kg} / \mathrm{m}^{2}$ and skinfold thickness at the front of the thigh $18.26 \pm 4 \mathrm{~mm}$. The volunteers were considered to be healthy after undergoing clinical assessment (medical history and physical examination), conventional resting electrocardiogram, complete blood count, urinalysis and clinical biochemical screening tests (glycose, uric acid, total cholesterol and LDL, HDL and VLDL fractions, and triglycerides), chest $\mathrm{X}$-ray and an ergometric test for cardiovascular assessment and determination of aerobic functional capacity.

The adequate number of subjects to be included in the study was obtained from a sample calculation using the Graph Pad StatMate v1.01 software (1998), which indicated a number of six volunteers. Our final sample included 10 subjects, who were selected from 48 volunteers. The individuals chosen were those who presented similar ages, levels of physical activity and anthropometric data, so as to ensure homogeneity in the group.

The volunteers received detailed information about the experimental protocol and its risks and objectives, and were familiarized with the tests. All the subjects signed an informed consent form before participating, and this study was approved by the Research Ethics Committee (Process No. 057/2000).

\section{Protocol}

The subjects were asked to abstain from any physical exercise during the 24 hours preceding the tests. Each volunteer performed four isometric exercise tests at MVC consisting of extension and flexion of the right and left knees in two sessions on nonconsecutive days, with the right and left legs and angles chosen randomly. Each test lasted $10 \mathrm{sec}$ and three repetitions were carried out for each angle tested, with intervals between repetitions that were sufficient to allow the HR to return to the control values that had been observed under resting conditions in the initial evaluation.

\section{Measurement of mean maximum torque}

The tests were carried out using a computerized dynamometer (Biodex Multi-Joint System 2, Biodex Medical Systems Inc., New York, USA), with the subject in a sitting position (hip fixed at an angle of $90^{\circ}$ ). They consisted of: 1) knee extension at an angle of $60^{\circ}, 2$ ) knee extension at an angle of $90^{\circ}, 3$ ) knee flexion at an angle of $30^{\circ}$, and 4) knee flexion at an angle of $90^{\circ}$. 
The lateral epicondyle of the femur was aligned with the rotation axis of the dynamometer. To minimize contraction of the muscles not directly involved in the tests, the trunk was stabilized with a transverse holding strap on the chest and another in the infraumbilical region. The distal region of the thigh was fixed to the seat and the leg was fixed to the lever arm of the dynamometer $(2 \mathrm{~cm}$ above the external malleolus).

The volunteers were instructed to keep their arms relaxed to avoid contraction of the other muscle groups not involved in the exercise, and to breathe spontaneously so as to avoid any subconscious Valsalva maneuver that might by itself change the central and reflex HR responses. The heart rate response was analyzed at the end of each test in order to investigate any occurrence of reflex bradycardia that might result from vagal retake occurring after the Valsava maneuver ${ }^{17}$, which did not occur. The subjects were asked to use maximum force throughout the period of MVC and were encouraged verbally by the examiner to sustain the torque value, which was also plotted in real time on the computer monitor placed in front of them and was used as visual feedback.

\section{Heart rate measurement}

The HR was obtained from an electrocardiogram. The signals were recorded in real time after analog-to-digital conversion (Lab-PC+, National Instruments Co.) and identification of the " $\mathrm{R}$ " peaks of the electrocardiogram waves; the R-R intervals were calculated on a beat-to-beat basis using custom-designed software ${ }^{18}$ and the successive HR and $\mathrm{R}-\mathrm{R}$ intervals were stored on hard disc. The volunteers were monitored using a modified MC5 lead, with self-adhesive disposable carbon electrodes. The HR was recorded for 65 sec while resting before each test, for 10 sec during MVC and for $120 \mathrm{sec}$ during recovery.

The tests were always carried out between 4:00 and 7:00 p.m. to prevent possible alterations in the results due to circadian influences. The room temperature was maintained between $22^{\circ}$ and $24^{\circ} \mathrm{C}$ and the relative air humidity in the laboratory was 42 to $54 \%$.

\section{Data analysis}

The mean maximum torque (MMT) obtained from each test was used in the torque data analysis. The HR analysis included HR measurement under resting condition before each exercise, throughout the sustained contraction and during the recovery period (120 sec after the exercise). The resting HR (beats/min.) corresponded to the mean values obtained during a period of $60 \mathrm{sec}$ immediately before the beginning of the exercise; the maximum HR response was expressed as the highest instantaneous value attained during the $10 \mathrm{sec}$ of exercise. The mean from the three repetitions was used for calculating the two variables studied (MMT and $\Delta \mathrm{HR}$ ).
As shown in the figures, $\Delta \mathrm{HR}$ corresponded to the increment between mean resting values and the mean obtained after 10 sec of isometric exercise.

\section{Statistical analysis}

The results are presented as box plots and are reported as medians, quartiles (first and third), minimums, maximums and outliers. Because of the non-Gaussian distribution, nonparametric tests were selected for statistical analysis: Friedman multiple comparison tests with Dunn post-hoc test, and Spearman rank correlation coefficients. The significance level was set at $\alpha=0.05$ for all tests. The statistical analysis was carried out using the Statistics for Windows software, version 5.5 (StatSoft, Inc., 1984-2000).

\section{RESULTS}

The MMT generated was significantly higher during MVC knee extension than during knee flexion, for both the right and left knees $(\mathrm{p}<0.05)$. No significant difference was observed in the MMT data obtained for knee flexion at the angles of $30^{\circ}$ and $90^{\circ}$ ( $\mathrm{p}>0.05$ ), or for knee extension at the angles of $60^{\circ}$ and $90^{\circ}$, for both the right and left knees (Figure 1).

The median resting HR immediately before the test was similar ( $p>0.05$ ) under all the conditions studied and no significant difference ( $p>0.05)$ in HR response variation was observed after $10 \mathrm{sec}$ of isometric exercise at MVC (Figure 2).

Figure 3 show the $\triangle \mathrm{HR}$ and MMT during isometric exercise at MVC under the two conditions studied, i.e., right and left knee flexion at the angles of $30^{\circ}$ and $90^{\circ}$ and extension at the angles of $60^{\circ}$ and $90^{\circ}$. No significant correlation was observed between the variables studied.

\section{DISCUSSION}

In the present study, no significant difference in MMT was observed between the two extension angles studied. These data are in agreement with the study by Silva et al. ${ }^{15}$, who did not find any significant difference in MMT between knee extension at the angles of $60^{\circ}$ and $90^{\circ}$ during isometric exercise tests at MVC. However, the present results contrast with those from investigations carried out by other authors $^{10-12,16}$, who observed higher peak torque at $60^{\circ}$ knee flexion, and by Suter \& Herzog ${ }^{13}$ and Bandy \& Hanten $^{14}$, who studied knee angles ranging from 15 to $90^{\circ}$ in $15^{\circ}$ increments and found the highest torque when the knee extensors were in the most elongated position $\left(90^{\circ}\right)$.

The knee flexion tests in the present study did not reveal any significant difference in MMT between $30^{\circ}$ and $90^{\circ}$ during the MVC. This finding is similar to those of Murray et al. ${ }^{10}$, who studied the joint angles of $30^{\circ}, 45^{\circ}$ and $60^{\circ}$. In contrast, 


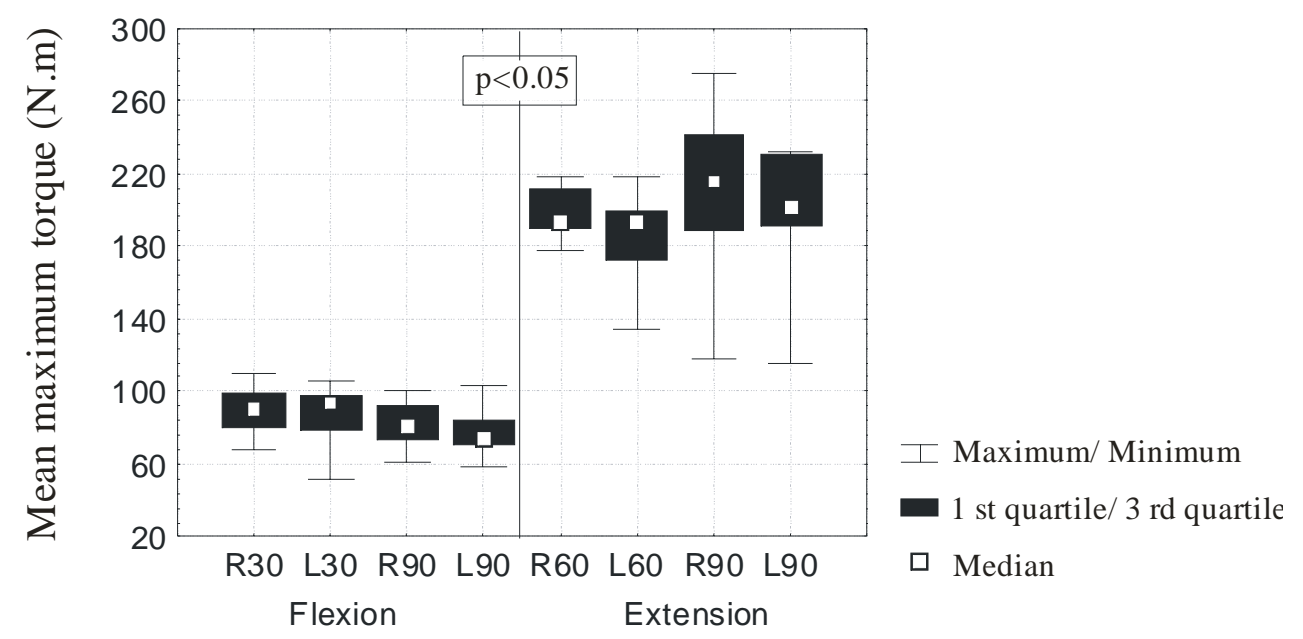

Figure 1. Mean maximum torque data (N.m) obtained for the subjects after 10s of maximum voluntary contraction (MVC) of right (R) and left (L) knee flexion at $30^{\circ}$ and $90^{\circ}$ and knee extension at $60^{\circ}$ and $90^{\circ}(n=10)$. Friedman multiple comparison tests were utilized with Dunn posthoc test $(\alpha=0.05)$. The MMT generated was significantly higher during MVC knee extension than during knee flexion, for both the right and left knees $(\mathrm{p}<0.05)$. No significant difference was observed in the MMT data obtained for knee flexion at the angles of $30^{\circ}$ and $90^{\circ}$ ( $>0.05$ ), or for knee extension at the angles of $60^{\circ}$ and $90^{\circ}$, for both the right and left knees.

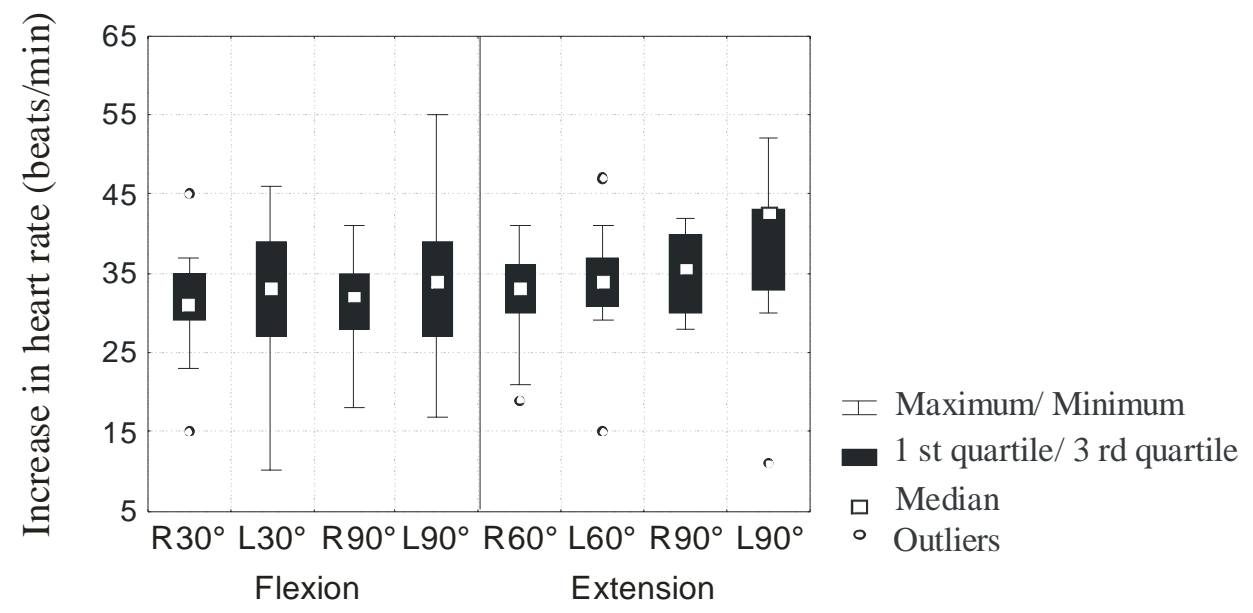

Figure 2. Heart rate variation ( $\Delta \mathrm{HR}$ - beats/min) after 10s of maximum voluntary contraction for right $(\mathrm{R})$ and left $(\mathrm{L}) \mathrm{knee}$ flexion at $30^{\circ}$ and $90^{\circ}$ and knee extension at $60^{\circ}$ and $90^{\circ}(n=10)$. Friedman multiple comparison tests were utilized with Dunn post-hoc test $(\alpha=0.05)$. No significant difference ( $p>0.05$ ) in HR response variation was observed after 10 sec of isometric exercise at MVC.

Yasuda \& Sasaki ${ }^{19}$ reported that the greatest external strength of the hamstring muscles was at an angle of $5^{\circ}$. However, it should be taken into account that the authors cited above ${ }^{10-14,19}$ used the peak torque value for analysis, i.e. the highest value observed during MVC. The methodology in the present study was different: the data were expressed as mean maximum values reached in each torque curve. The justification for this is that the mean maximum value is more representative of the force produced by the volunteer throughout the exercise period and thus more adequately satisfied the objective of the present study. This might be one of the reasons for the differences observed between the present torque data and those reported in the studies cited earlier, which showed variations in torque values at different angles.

Comparison of the MMT values between knee extension and knee flexion showed results similar to those reported in the literature ${ }^{3,19}$ thus indicating greater force generation capacity for the quadriceps than for the knee flexors. This might be explained by morphological differences, since the quadriceps muscles with their relatively high degree of pennation, large cross-sectional area with predominantly type II fibers seem to be adapted for generation of great force, while flexor muscles with their relatively long, predominantly type I fibers and intermediate cross-sectional area seem to be designed for large movements and exercises that require 


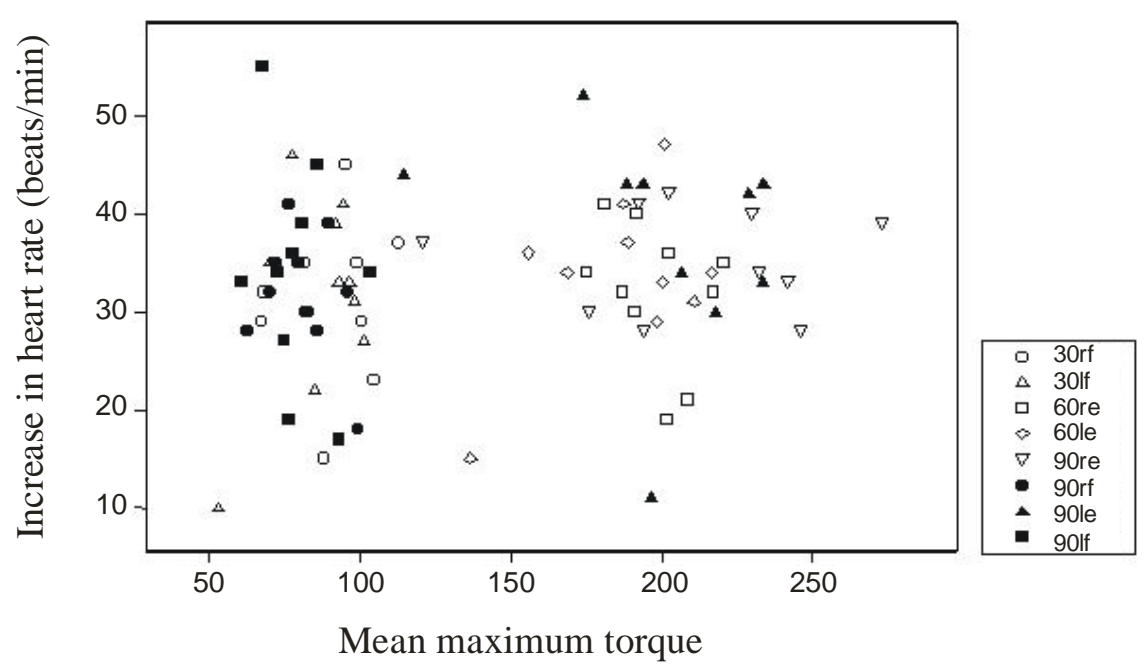

Figure 3. Scatter plot between mean maximum torque (N.m) and heart rate (DHR - beats/min) responses after 10s of maximum voluntary contraction of right and left knee flexion and extension. Legend: $(\bigcirc)$ right knee flexion at $30^{\circ} ;(\Delta)$ left knee flexion at $30^{\circ}$; $(\square)$ right knee extension at $60^{\circ}$; $(\diamond)$ left knee extension at $60^{\circ} ;(\nabla)$ right knee extension at $90^{\circ} ;(\bullet)$ right knee flexion at $90^{\circ} ;(\boldsymbol{\Delta})$ left knee extension at $90^{\circ}$; $(\boldsymbol{\square})$ left knee flexion at $90^{\circ}$.

a higher resistance to fatigue. We intend to carry out a magnetic resonance study in the near future to quantify the muscle mass and thereby correlate torque and muscle mass.

Additionally, just as in Thomée et al. ${ }^{20}$, no significant differences in torque values were found between the left and right legs in the present study, when comparing data obtained during MVC at the same joint angles. This might be attributed to the fact that the maximum voluntary activation of the motor units did not differ between the dominant and non-dominant legs during isometric exercise tests at MVC.

With regard to cardiovascular responses induced by isometric physical exercise, it has been well established in the literature ${ }^{2,21}$ that this type of exercise causes marked variations in HR due to activation of central neural mechanisms originating from efferent signals that are derived from the motor cortex, and activation of peripheral mechanisms consisting of afferent signals originating from the contracted muscles. A similar HR response pattern was observed in all tests, independent of the joint angle or the direction of force (flexion or extension) in the present study, and this corroborated other studies ${ }^{1,3,4,22}$. These findings during shortduration isometric exercise at MVC are attributed to the inhibition of vagal tonus acting on the heart due to central pathway irradiation ${ }^{1,4}$.

Regarding the magnitude of the HR response during isometric exercise at MVC, our results are in agreement with those reported by $\mathrm{Ng}$ et al. ${ }^{16}$ and Silva et al. ${ }^{15}$, who showed that the $\Delta \mathrm{HR}$ magnitude is independent of the joint angle. On the other hand, our results disagree with those obtained by Silva et al. ${ }^{3}$, who found a higher HR response magnitude during isometric MVC of knee extension at $90^{\circ}$, than in knee flexion at the same joint angle. Despite the similarity between the present protocol and the one used by those authors, it should be emphasized that they did not quantify the torque or force developed by the subject. The similarity in HR variation in response to isometric exercise observed for the knee flexor and extensor groups suggests that morphofunctional differences between these muscle groups do not influence the HR response during isometric exercise tests at MVC. This is in agreement with the findings of McCloskey \& Streatfeild ${ }^{23}$, who showed that the relative intensity of muscle contraction and not the muscle mass determines the cardiovascular responses relating to central pathway mechanisms. However, these results disagree with those reported by others authors ${ }^{2,21}$, who demonstrated that HR responses depend on muscle mass. It should be taken into account that the experimental protocols used by those authors differed from what was used in the present study, in terms of the muscle groups studied and in terms of intensity (percentage MVC).

It is important to point out that, in the present study, the volunteers were instructed to maintain continuous respiration throughout the exercise, thereby avoiding Valsalva maneuvers. This is an additional causal factor for the differences observed, since there are studies in the literature that avoid this maneuver ${ }^{1,3,15}$ or allow it during isometric exercise.

In conclusion, the present data has shown that, despite the tachycardia induced by isometric exercise, there is a lack of correlation between HR and MMT responses. On the whole, the data support the view that the rapid increase in HR during the 10 sec of isometric MVC occurred irrespective of the joint angle and the morphofunctional differences between the two muscle groups studied.

Acknowledgements: Profa. Dra. Stela Matiello, for the utilization of the electronic dynamometer; and to Dr. Carlos Mega for the clinical evaluation. 
Support: Research supported by CAPES, CNPq (520610/99 - SU and 300528/85-0) and FAPESP (01/07427-2).

\section{REFERENCES}

1. Maciel BC, Gallo Jr L, Marin-Neto JA, Martins LEB. Autonomic nervous control of the heart rate during isometric exercise in normal man. Pflügers Archives. 1987;408:173-7.

2. Seals DR, Washburn RA, Hanson PQ, Painter PL, Nagle FJ. Increased cardiovascular response to static contraction of larger muscle groups. J Appl Physiol. 1983;54(2):434-7.

3. Silva E, Oliveira L, Catai AM, Ferreira-Filho P, Bérzin F, Gallo $\mathrm{Jr}$ L. Evaluation of eletromyographic activity and heart rate responses to isometric exercise. The role played by muscular mass and type. Braz J Med Biol Res. 1999;32(1):115-20.

4. Maciel BC, Gallo Jr L, Marin-Neto JA, Martins LEB. Leg endurance training has no effect on the autonomic control of heart rate during isometric exercise. Braz $\mathrm{J}$ Med Biol Res. 1989;22:225-32.

5. Lind AR, Mcnicol GW. Circulatory responses to sustained handgrip contractions performed during other exercise, both rhythmic and static. J Physiol. 1967;192:595-607.

6. Fisher NM, Pendergast DR, Calkins EC. Maximal isometric torque of knee extension as a function of muscle length in subjects of advancing age. Arch Phys Med Rehabil. 1990;71:729-34.

7. Ebersole KT, Housh TJ, Johnson GO, Evetovich TK, Smith DB, Perry SR. MMG and EMG responses of the superficial quadriceps femoris muscles. J Electrom Kinesiol. 1999;9: 219-27.

8. Pincivero DM, Salfetnikov Y, Campy RM, Coelho AJ. Angleand gender-specific quadriceps femoris recruitment and knee extensor torque. J Biomech. 2004;37(11):1689-97.

9. Debrosses K, Babault N, Scaglioni G, Meyer J, Pousson M. Neural activation after maximal isometric contractions at different muscle lengths. Med Sci Sports Exerc. 2006;38(5): 937-44.

10. Murray MP, Gardner GM, Mollinger LA, Sepic SB. Strength of isometric and isokinetic contractions. Phys Ther. 1980;60(4):413-9.

11. Kues J, Rothstein J, Lamb RL. The relationships among knee extensor torques produced during maximal voluntary contractions under various test conditions. Phys Ther. 1994;74:674-83.
12. Narici MV, Hoppeler H, Kayser B, Landoni L, Claassen H, Gavardi C, et al. Human quadriceps cross-sectional area, torque and neural activation during 6 months strength training. Acta Physiol Scand. 1996;157:175-86.

13. Suter E, Herzog W. Extent of muscle inhibition as a function of knee angle. J Electrom Kinesiol. 1997;7(2):123-30.

14. Bandy WD, Hanten WP. Changes in torque and electromyographic activity of the quadriceps femoris muscles follwing isometric training. Phys Ther. 1993;73(7):455-67.

15. Silva E, Honório ML, Teixeira LCA, Catai AM, Oliveira L, Quitério RJ. Relação entre torque e freqüência cardíaca durante exercício isométrico de extensão do joelho em diferentes ângulos. IX Congresso Brasileiro de Biomecânica; 2001 Sep 13-15; Gramado, RS. Brasil: UFRGS; 2001. p. 02.

16. Ng AV, Agre JC, Hanson P, Harrington MS, Nagle FJ. Influence of muscle length and force on endurance and pressor responses to isometric exercise. J Appl Physiol. 1994;76(6):2561-9.

17. Marães VRFS, Santos MDB, Catai AM, Moraes FR, Oliveira L, Gallo-Jr L, et al. Modulação do sistema nervoso autônomo na resposta da freqüência cardíaca em repouso e à manobra de Valsalva com o incremento da idade. Rev Bras Fisioter. 2004;8(2):97-103.

18. Silva E, Catai AM, Trevelin LC, Guimarães JO, Silva Jr LP, Silva LMP, et al. Design of computerized system to evaluate the cardiac function during dynamic exercise. Phys Med Biol. 1994;33:409.

19. Yasuda K, Sasaki T. Exercise after anterior cruciate ligament reconstruction: the force exerted on tibia by the separate isometric contractions of the quadriceps or the hamstrings. Clin Orthop Rel Res. 1987;220(7):275-83.

20. Thomeé R, Renström P, Karisson J, Grimby G. Patellofemoral pain syndrome in young women. Scand J Med Sci Sports. 1995;5:245-51.

21. Mitchell JH. Neural control of the circulation curing exercise. Med Sci Sports Exerc. 1990;22(2):141-54.

22. Quitério RJ, Catai AM, Moraes FR, Oliveira L, Teixeira LCA, Silva E. Correlação entre as respostas da freqüência cardíaca, do torque e do sinal eletromiográfrico ao exercício isométrico de flexão do joelho. Rev Soc Cardiol Estado de São Paulo. 2004;13(3A):2-14.

23. McCloskey DI, Streatfeild KA. Muscular reflex stimuli to the cardiovascular system during isometric contractions of muscle groups of different mass. J Physiol. 1975;250:431-41. 